\title{
Lágrimas de papel: Mestre Pastinha e os regimes de afeto no jornalismo impresso ${ }^{1}$
}

\section{Denise da Costa Oliveira Siqueira}

Universidade do Estado do Rio de Janeiro, Programa de Pós-Graduação em Comunicação, Rio de Janeiro, RJ, Brasil

ORCID: https://orcid.org/0000-0001-7501-7390

\section{Fábio Grotz Majerowicz}

Universidade do Estado do Rio de Janeiro, Programa de Pós-Graduação em Comunicação, Rio de Janeiro, RJ, Brasil

ORCID: https://orcid.org/0000-0003-3196-450X

\section{Raquel Gonçalves Dantas}

Centro Universitário Módulo, Caraguatatuba, SP, Brasil

ORCID: https://orcid.org/0000-0001-5462-6592

\begin{abstract}
Resumo
Emoções, sentimentos e afetos são fenômenos mediados socialmente, processados no amplo teatro das relações humanas. O jornalismo compõe tal fenômeno, contribuindo para a produção, reprodução e ressignificação de sensibilidades. Este artigo tem como objetivo refletir sobre a expressão de emoções em material jornalístico, entendendo que os afetos identificados dizem respeito ao ato de sentir uma emoção, mas também à experiência simbólica e midiatizada do corpo e de suas práticas. Em termos metodológicos, nossa reflexão se constrói a partir da leitura de um conjunto de matérias antigas abordando os últimos anos de vida de Mestre Pastinha, um dos nomes mais importantes da Capoeira Angola no Brasil. Para fins de análise, neste artigo são estudados detalhadamente dois desses textos jornalísticos, tendo como problemática a indagação sobre que sentidos podem ser construídos partindo de uma articulação do corpo, das emoções e da produção midiática. Esta é a questão de fundo que instiga a reflexão e a análise propostas no artigo. $O$ estudo se fundamenta na antropologia das emoções, tomando afetos como registros culturalmente condicionados que derivam antes do repertório de um grupo social do que de forças naturais ou espontâneas.
\end{abstract}

\footnotetext{
1 Este artigo constitui uma discussão ampliada e aprofundada de um trabalho preliminar apresentado no $40^{\circ}$ Congresso Brasileiro de Ciências da Computação, INTERCOM, em Curitiba, PR, 2017.
} 


\section{Palavras-chave}

Narrativa. Antropologia das emoções. Corpo. Capoeira Angola.

Produção de sentidos.

\section{Introdução}

Fator constituinte da organização social contemporânea, os meios e aparatos sociotécnicos de comunicação ajudam a inventar a realidade ao atuar na produção, reprodução, difusão e reconstituição de sentidos. Nesse âmbito, o jornalismo pode ser pensado como uma espécie de radar por meio do qual é possível captar sinais de uma sociedade e de um tempo, identificando acontecimentos, visões de mundo, dissensos e paixões que atravessam grupos sociais.

Partindo desse olhar, o jornalismo constituiria um eixo ordenador da realidade, um ofício com densidade cultural. Essa é a perspectiva de Martín-Barbero, para quem "a possibilidade de compreender o que realmente se passa na imprensa tem tanto ou mais a ver com o que realmente se passa na fábrica e na taberna, nos melodramas e nos comícios com seu alarido, com suas faixas e panfletos, que com o que se passa no mundo dos periódicos mesmo" (2009, p. 117). O pressuposto do autor está centrado na condição social, processual e dinâmica do mundo da qual os meios fazem parte. Conforme essa abordagem, os meios - impressos, audiovisuais ou eletrônico-digitais - constituem encarnações de um período histórico e convivem no bojo de processos simbólicos em relação aos quais são, ao mesmo tempo, causa e consequência, interagindo com um amplo conjunto de manifestações e fenômenos sociais.

0 pensamento de Martín-Barbero abre espaço para que se pense a própria ideia de meio de comunicação como algo mais amplo, que não se restrinja à produção jornalística ou aos veículos. Assim, é forçoso pensar que a mediação também constitui um processo que diz respeito ao corpo. Por essa ótica, a condição midiática não é própria apenas aos espaços digitais ou ao papel jornal, mas também à materialidade do corpo, seus sons e movimentos, ao mundo biológico, ao mundo cultural e suas manifestações simbólicas, tais como os sentimentos e sensações. Tal abordagem pode ser fundamentada tanto por pensadores da Antropologia - como Le Breton $(2004,2007,2009)$ - quanto da Comunicação - como Barbosa (2013) e Siqueira (2015). 
A partir dessas ideias, este artigo propõe uma discussão sobre antigas matérias jornalísticas acerca de Mestre Pastinha, uma figura de relevância cultural calcada em seu trabalho com o corpo em prol da Capoeira Angola². Sua vida foi documentada por farto material jornalístico impresso e, particularmente, sua morte na pobreza e na solidão foi um tema de significativo interesse jornalístico. No momento atual em que novas configurações ganham espaço na capoeira, com destaque para o importante papel das mulheres e das primeiras mestras reconhecidas (DANTAS, 2019), olhar as emoções em torno da morte de um precursor, 40 anos atrás, mostra-se importante.

Nos dez anos anteriores a sua morte, acontecida no início dos anos 1980, dezenas de matérias foram veiculadas na mídia comercial sobre Mestre Pastinha. Conforme o acervo do site especializado Velhos Mestres ${ }^{3}$, pelos menos 15 reportagens foram publicadas em alguns dos principais veículos impressos brasileiros da época - O Globo, Jornal do Brasil, Jornal da Bahia, Revista Fatos e Fotos, Jornal O Movimento, Jornal Última Hora. Os textos possuíam caráter de denúncia das condições precárias de vida do "guardião da capoeira", após o despejo de Pastinha do casarão onde ministrava aulas, durante a reforma arquitetônica do Pelourinho, em Salvador, na Bahia.

Notícias sobre o reajuste da aposentadoria concedida pelo governo a Pastinha para três salários-mínimos; a ameaça do desaparecimento da capoeira frente ao sucesso das academias de lutas orientais; a saúde debilitada e as internações; perfis sobre a vida do Mestre; o legado cultural deixado por ele foram assuntos estampados em páginas de jornais e revistas brasileiros durante sua última década de vida, entre 1971 e 1981. Para fins de metodologia, este artigo examina, a partir de uma abordagem de análise das narrativas combinada à reflexão sobre critérios de noticiabilidade e com fundamentação na antropologia das emoções, duas matérias publicadas próximas à morte de Pastinha, em 13 de novembro de 1981. Uma delas, veiculada pelo Jornal do Brasil, em 26 de fevereiro de

\footnotetext{
2 A Capoeira Angola constitui uma prática construída a partir de elementos corporais, musicais e espirituais de matrizes africanas trazidos para o Brasil por pessoas escravizadas. Mestre Pastinha foi um dos fundadores e um dos principais difusores dos fundamentos da Capoeira Angola. A Capoeira Regional, por sua vez, teve em Mestre Bimba um de seus principais expoentes. Ele desenvolveu uma metodologia, incluiu elementos de artes marciais, inseriu o sistema de cordas, treinos de alto rendimento, transformando a capoeira em uma modalidade esportiva. 0 modelo casou muito bem com os objetivos políticos nacionalistas de Getúlio Vargas, que denominou a Capoeira Regional esporte "genuinamente brasileiro", difundindo a prática e projetando-a internacionalmente. Atualmente, há inúmeras formas e apropriações da prática, entre elas a capoeira contemporânea, que mescla as duas modalidades.

3 As duas reportagens foram extraídas da página virtual "Velhos Mestres" - que disponibiliza uma pesquisa ampla sobre mestres da capoeira como Pastinha, Besouro, Waldemar, Gato Preto e Cobrinha Verde. Na aba sobre Pastinha há uma quantidade significativa de matérias publicadas em jornais e revistas ao longo da vida do mestre, além de fotografias de acervos de jornalistas, intelectuais, amigos e familiares. Link para o site: http://velhosmestres.com/index2. Acesso em $25 / 05 / 2020$
} 
1980 (Aos 90 anos, cego e doente, Pastinha obtém alta do Hospital); a segunda, veiculada pela revista Placar, de dezembro de 1979 (Saravá, Mestre Pastinha! O triste fim do rei da capoeira).

O objetivo do artigo é promover uma reflexão sobre a construção social das emoções em veículos impressos e sobre o estatuto simbólico e midiático do corpo, reconhecendo que trata-se de fenômenos fundamentalmente sociais. Isto é, a produção midiática jornalística está inserida em um complexo de mediações que inclui, entre outros aspectos, regimes de afetos e sentimentos. Desse modo, considera-se que há um contínuo simbólico que entrelaça corpo, publicações jornalísticas e afetos em uma mesma dinâmica cultural. Pretende-se refletir acerca da sobreposição dessas três esferas no contexto social da época de publicação das matérias. Que sentidos podem ser construídos partindo de uma articulação do corpo, das emoções e da produção midiática? Esta é a questão de fundo que instiga a reflexão e a análise propostas no artigo.

Entende-se que o jornalismo se configura como um fenômeno social, calibrado pela sociedade, com múltiplas dinâmicas que lhe conferem competência para constituir e, ao mesmo tempo, ser constituído pela sociedade (MARTÍN-BARBERO, 2009; SILVA, 2005; TRAQUINA, 2012). Ou, para colocar em evidência outros pensadores que refletem sobre a condição cultural da mídia impressa, aqui parte-se do entendimento de que debater a condição dos jornais é reconhecer que houve uma "civilização" do jornal, erigida sobretudo a partir do século XIX, que produziu efeitos sobre a vida social e mesmo sobre a configuração de mentalidades (KALIFA; RÉGNIER; THÉRENTY; VAILLANT, 2011). Um imaginário de papel, podemos dizer, cuja matriz física e dobrável é profundamente versátil na modulação imaterial (simbólica) do mundo. Como referencial teórico, também recorre-se a leituras do antropólogo David Le Breton $(2009,2007)$, para quem o corpo e as emoções são eventos que só podem ser compreendidos no contexto de um regime simbólico.

0 artigo constitui, portanto, um esforço de investigação que reúne jornalismo, corpo e emoções para refletir sobre a forma como se abordou a vida de Mestre Pastinha nas matérias publicadas nos dois veículos impressos. São observados os recursos estilísticos utilizados, a ênfase dada aos aspectos emocionais da notícia, as fontes utilizadas, além do tratamento da imagem e do corpo em cena. Antes da análise, fazemos uma leitura da imprensa em sua articulação com padrões emotivos e regimes de sentimentos que compõem um possível perfil afetivo socialmente construído no Brasil desde o século XIX. 


\section{Raízes de um jornalismo de emoções e afetos}

No Brasil de grandes mudanças políticas e sociais do século XIX - da transição de colônia à nação independente, da passagem pelo período da regência, da luta pela abolição da escravatura e, finalmente, da transição de Monarquia à República - há também um percurso de grandes transformações na mídia impressa. Jornais e revistas participaram da constituição do país, de suas instituições e sociabilidades (MOREL, 2016).

O modo panfletário com que a imprensa se colocava publicamente, em meados do século XIX, chama a atenção. Xingamentos, textos injuriosos e disputas compunham o cenário social da imprensa de um país que buscava se consolidar e firmar uma identidade. Tais características presentes nos jornais também contribuíram para moldar parte da sociabilidade brasileira. A comunicação crispada, irascível politicamente, dava o tom naquele ambiente. Circulavam pasquins e folhas incendiárias, em uma atmosfera exasperada ligada não apenas às ebulições do mundo político e do poder.

Estava em marcha, conforme Vaillant (2011) observa acerca da condição simbólica geral dos impressos na França, o recurso à polêmica como uma via de autopromoção dos jornais. Assim, nas batalhas retóricas travadas pelo papel, os jornais se consolidavam como mídia, como espaço privilegiado de descrição e construção da realidade social, enquanto, paralelamente, contribuíam para a encenação dramática do mundo simbólico. Nessa atmosfera de inquietação, as emoções fulminantes e abrasivas delineavam certos contornos da emergente esfera pública e letrada.

Em meio a ataques e desqualificações grosseiras que povoavam um imaginário de intolerância, em um país escravocrata, o corpo adquiria sentidos e simbologias peculiares. Conforme Morel (2016), os insultos faziam parte de um panorama cultural em que a racionalidade das ideias iluministas europeias do século XVIII era considerada como sistema de pensamento ideal para o progresso do país. Assim, no cenário de ofensas, brasileiros e portugueses, por exemplo, alcunhavam-se uns aos outros delineando uma espécie de zoologia política. A corporeidade era consumida pelas metáforas, por uma simbologia marcadamente afetiva. Portugueses eram chamados por brasileiros de "camelos"; brasileiros, por sua vez, eram chamados por portugueses de "bodes". 0 outro era tido como inimigo do progresso e, portanto, tido como inumano, monstro, despossuído de razão, atacado em sua corporeidade, colocando em circulação uma gama de sentidos e afetos 
irados e pejorativos. Curiosamente, em um ambiente que se pretendia racionalista e "imunizado" contra emoções e paixões, os afetos grassavam.

Note-se como o corpo era uma questão fundamental no processo social, ligado a uma dinâmica de conhecimento e saber mais complexa. 0 país começava a se constituir e o referencial racional varria as relações sociais como marco filosófico padrão. À margem disso, restava o infortúnio, a desgraça, o retrocesso, os monstros e animais. Havia, portanto, uma presunção da racionalidade como sistema de pensamento mais ajustado e qualificado para enxergar, compreender e controlar a realidade.

0 procedimento cartesiano de interessar-se por algo, observar, verificar, testar e comprovar era considerado como um roteiro de conhecimento infalível. A variante radical desse racionalismo, o positivismo, fincava-se no mundo impresso, nas interpretações das relações sociais, espalhando ideias de superioridade, racistas e eugênicas, e delineando no horizonte uma série de corpos marginais, desviantes e ameaçadores. 0 imaginário de papel abastecia de emoções o regime afetivo de um Brasil que fazia suas primeiras incursões no terreno do mundo moderno.

Como não se inquietar com um mundo supostamente racional, metódico, mas que, paradoxalmente, parecia funcionar menos como um regime de ideias racionais do que como um sistema de ideias passionais, eivadas de intolerância? Por meio dessa dinâmica, surgia a esfera pública e letrada no país, e o jornalismo contribuía para narrar e compor a realidade social a partir de considerações tanto racionais quanto emocionais.

Em uma perspectiva contemporânea da antropologia das emoções, para Le Breton (2009, p.121), as esferas "racional" e "emocional" não são inconciliáveis. Conforme o autor, "no terror que contagia uma multidão, na raiva racista ou nas manifestações de furor individual ou coletivo, não há triunfo da 'irracionalidade' ou da 'natureza', mas a aplicação de um raciocínio e de uma lógica mental ao meio social”. Assim é que, para Le Breton (2004), as emoções possuem suas próprias razões.

$\mathrm{Na}$ mesma linha de pensamento, o binarismo sensível versus razão, conforme François Laplantine (GÉLARD, 2017), constitui uma inadequação epistemológica, pois não há relação de dominância. 0 sensível, a subjetividade e os desejos - em outras palavras, aquilo que não é considerado objetivo e inteligível - só existem porque foram provocados pela ambiência que circunda os indivíduos, cuja racionalidade se desenvolve também através dessa ambiência. 
A história do jornalismo ilustra como o corpo e as emoções estão socialmente enraizados. De acordo com Angrimani (1995), imprensa e sensacionalismo nasceram simultaneamente. No século XVI, jornais franceses privilegiavam notícias e histórias consideradas catastróficas, bizarras, incomuns, engraçadas, enfim, emotivas. Cenário semelhante ocorreu nos EUA, no final do século XIX, com destaque para os jornais New York World e Morning Journal, cujas narrativas eram povoadas por notícias de crimes, acidentes e dramas (AMARAL, 2006). No Brasil, o século XX é caracterizado, entre outros fatores, pelo surgimento dos chamados jornais populares, que enfatizavam em seu cardápio noticioso a "exploração desse fascínio pelo extraordinário, pelo desvio, pela aberração, pela aventura" (PEDROSO, 2001, p.5).

Nas reflexões de Roland Barthes (1964), tal regime de notícias é denominado de fait divers e se diferencia de outras notícias por constituir uma informação total, imanente, de consumo rápido e imediato. Isso significa que o fait divers constitui um registro simbólico notadamente afetivo, atravessado por tensões que não existem a priori. Fait divers é uma modalidade de notícia, e nenhuma notícia é considerada notícia espontaneamente, como uma emanação natural, autoevidente. O conteúdo do fait divers "não é estrangeiro ao mundo: desastres, assassinatos, sequestros, agressões, roubos, esquisitices, tudo isso remete ao homem, a sua história, a sua alienação, a seus fantasmas, a seus sonhos, a seus medos" (BARTHES, 1964, p.225).

Para Ambroise-Rendu (2011, p.989), o fait divers constitui uma maneira de conferir cotidianidade ao extraordinário, investindo em uma sensibilidade, sobretudo quando ilustrada e visual, que "hesita entre os bons sentimentos e o voyeurismo macabro". Nesse sentido, é possível observar na prática jornalística efeitos sociais pois, de acordo com Traquina (2012, p.29), "os jornalistas interagem silenciosamente com a sociedade, por via dos limites com que os valores sociais marcam as fronteiras entre normal e anormal, legítimo e ilegítimo, aceitável e desviante".

Nessa conjuntura de disputas e estratégias para produção de sentidos nos materiais jornalísticos, também começam a se consolidar disputas profissionais. No início do século $\mathrm{XX}$, surgem as primeiras discussões sobre a regulamentação da profissão e a busca por técnicas que possibilitassem uma escrita com características mais objetivas e menos retóricas. 
A partir desse contexto histórico, o jornalismo impresso brasileiro consolidou-se empresarialmente ao longo do século XX (SODRÉ, 1999). Aparatos técnicos sofisticados e a demarcação social da identidade do jornalista e do ofício do jornalismo fomentaram uma esfera pública que deu continuidade e expandiu culturalmente o regime de afetos estruturante da vida social brasileira.

0 regime noticioso continuaria a privilegiar determinadas emoções tipicamente sensacionalistas, da modalidade do fait divers, no âmbito de uma sociedade moldada em torno de sentimentos abastecidos de um lado pela tragédia e pela dor, do outro, pela piedade e pela compaixão. No início dos anos 1980, uma parte da história da capoeira no Brasil, em especial os últimos dias de Mestre Pastinha, noticiados como tristes e dolorosos, foi capturada pela imprensa brasileira.

\section{Mestre Pastinha e o jornalismo que afeta}

No final dos anos 1970, praticantes, jornalistas e interessados em capoeira que acompanharam os passos de mestre Bimba, maior representante da Capoeira Regional no país, viram a expansão da prática dentro e fora do Brasil. A mesma política de Estado que denominou a Capoeira Regional de "esporte genuinamente brasileiro" e agiu em prol da inserção social dessa modalidade em vários espaços como universidades, academias e bairros de classe média, ainda na década de 1930, também abafou ${ }^{4}$ a divulgação da prática como uma manifestação de resistência cultural de origem afro-brasileira.

Pastinha, um dos mestres representantes da tradicional Capoeira Angola, sem o apoio destinado à Capoeira Regional, viveu os últimos anos de sua vida em situação de pobreza. É a partir desse quadro que este artigo situa brevemente a Capoeira Angola no final dos anos 1970 e início dos anos 1980, época em que as matérias analisadas foram escritas. Parte-se de um olhar que entende que "as emoções são modo de afiliação a uma comunidade social, uma maneira de se reconhecer e de poder se comunicar em conjunto sobre a base da proximidade sentimental" (LE BRETON, 2009, p. 126).

\footnotetext{
4 Somente em meados dos anos 1980, depois da morte de Mestre Pastinha, a Capoeira Angola saiu do ostracismo e iniciou um processo de retorno, com novos alunos e alunas interessados em recuperar a memória, os ensinamentos e a prática de Pastinha.
} 
Figura 1 - Matéria publicada no Jornal do Brasil

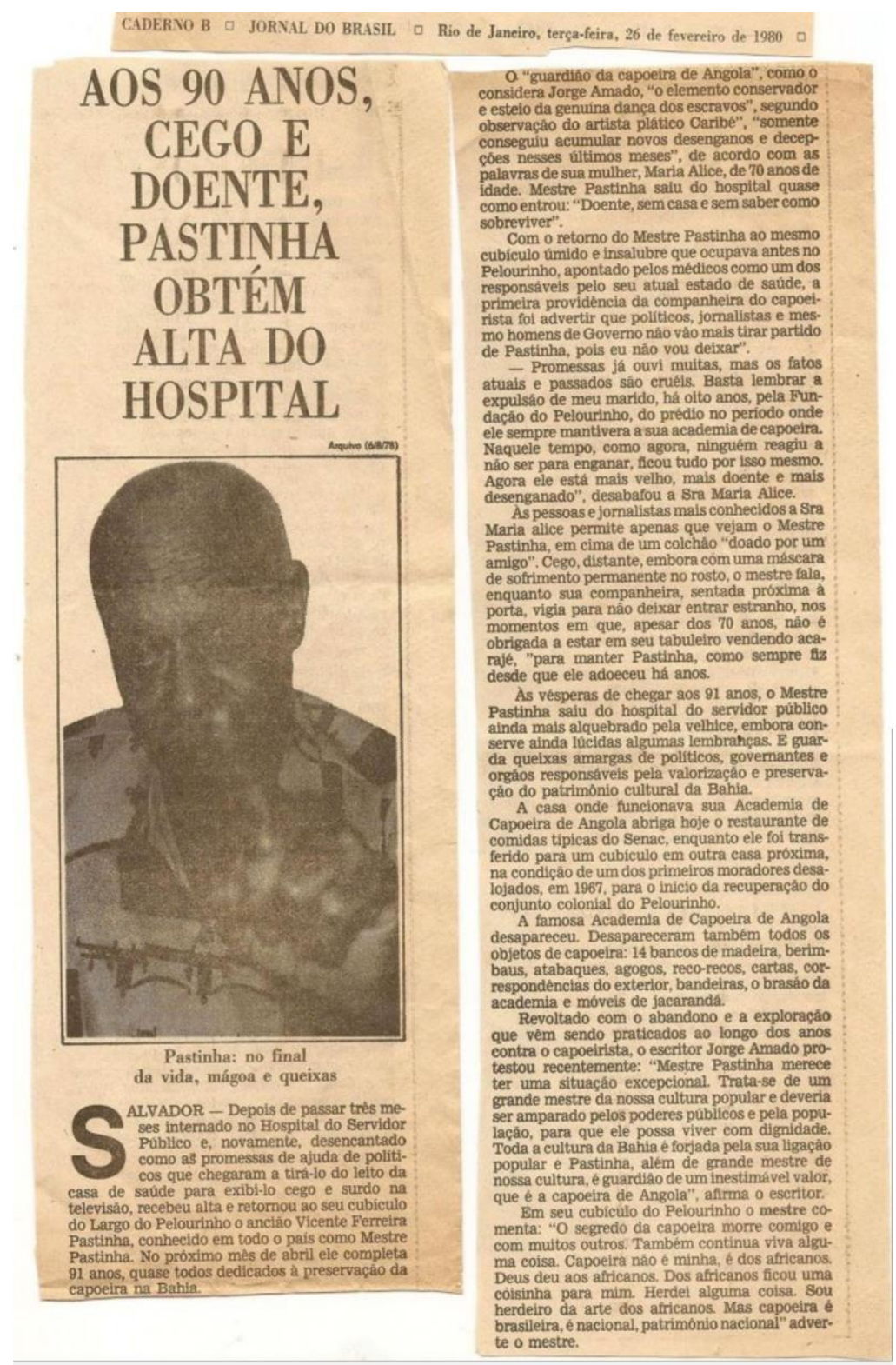

Fonte: Aos 90 anos... (1980).

Na matéria publicada no prestigioso Caderno $B^{5}$, caderno de jornalismo cultural do Jornal do Brasil, em 26/02/1980 (figura 1), o título anuncia uma circunstância de desolação: "Aos 90 anos, cego e doente, Pastinha obtém alta do hospital". A foto retrata um velho franzino, de olhar baixo e dedo apontado. 0 título destaca o corpo debilitado, que acabara de passar três meses em um hospital. A legenda da foto enfatiza a vida próxima do fim, as

\footnotetext{
5 De acordo com Ferreira (2008), o Caderno B constituiu um espaço importante para a captação e ampliação do cotidiano.
} 
queixas e as mágoas. As primeiras informações sugerem uma matéria triste e desanimadora sobre "o guardião da capoeira de Angola", como o qualificou o escritor Jorge Amado em declaração citada na matéria.

O texto jornalístico se apresenta engajado em fazer uma denúncia, uma notícia interpretativa sobre a saúde, as condições de sobrevivência e o descaso dos órgãos públicos com a vida de Vicente Ferreira Pastinha. Uma angulação que se propõe a despertar emoções no leitor, usando uma construção linguística costurada e recorrendo ao imaginário sensível de uma merecida velhice distinta, incompatível com o desamparo em que o mestre se encontrava. Parafraseando Cremilda Medina (1988), pode-se acrescentar que a matéria contém uma pitada de "ingredientes de consumo". Há no texto um evidente tom emotivo, abastecido por uma vida terminal apresentada em tragédia e desgraça. Vale ressaltar que os meios de comunicação trabalham com o pressuposto de um senso de justiça do "gosto médio". Portanto, a angulação não se deve apenas à formulação da notícia, "mas ao próprio conteúdo - dados significativos da realidade que passam para a representação" (MEDINA, 1988, p. 75).

Já no primeiro parágrafo do texto, o repórter recorre a uma informação que expõe uma situação de uso da imagem daquele corpo frágil, causando comoção e ativando o campo da sensibilidade dos leitores: "desencantado com as promessas de ajuda de políticos que chegaram a tirá-lo do leito da casa de saúde para exibi-lo cego e surdo na televisão". A captação das informações e a decisão do uso de algumas delas no início do texto, principalmente aquelas que reforçam a superexposição da imagem de Pastinha ao assédio midiático e a interesses políticos, agem diretamente no campo emocional do leitor. Há um apelo emotivo a partir da seleção das informações, somado às reproduções de falas das fontes.

O escritor Jorge Amado, o artista plástico Caribé, Pastinha e sua esposa Maria Alice, vendedora de acarajé, encerram a matéria. Os informantes reproduzem a indignação e o tom de denúncia definido previamente pela angulação da pauta. A credibilidade das fontes, representantes emblemáticas da cultura na Bahia, transmite confiança e segurança aos leitores. Ao denominarem Pastinha de mestre da cultura brasileira e detentor de um conhecimento de muito valor, elas garantem o fio condutor delineado pelo(a) repórter para a construção da notícia. Dessa maneira, contribuem para uma espécie de regime jornalístico de sentimentos ou regime de afetos, disseminando aquilo que Le Breton (2009, p. 126) 
denomina de saber afetivo, "que circula por intermédio das relações sociais e ensina aos atores as impressões e as atitudes que se impõem, de acordo com suas sensibilidades sociais, nas diferentes vicissitudes que podem afetar suas histórias".

Em uma leitura da matéria inspirada na antropologia das emoções, pode-se pensar que o texto jornalístico acessa um lugar nas emoções coletivas construídas socialmente que gera uma interpretação funcional. A denúncia da pauta é feita não apenas a partir do recorte representado da realidade, mas também ao acessar emoções socialmente familiares. Há um jogo midiático dos afetos por meio do qual o jornal busca estabelecer um diálogo com a sociedade recorrendo à linguagem afetiva comum representada nos valores e afetos que perpassam os sujeitos via grupo social. Ao debruçar-se criticamente e racionalmente sobre as informações do texto, o indivíduo é afetado também pelo "poder comunicativo das emoções" (SIQUEIRA, 2015, p. 23).

Ao final da matéria, o repórter reproduz o depoimento do próprio Pastinha, falando do conhecimento da Capoeira Angola: "A capoeira não é minha, é dos africanos. Deus deu aos africanos. Dos africanos ficou uma coisinha pra mim. Herdei alguma coisa. Sou herdeiro da arte dos africanos. Mas a capoeira é brasileira, é nacional. É patrimônio nacional". A escolha por terminar a matéria com uma exaltação à Capoeira Angola e às suas matrizes africanas na voz daquele que está perto da morte e em condições precárias de vida, não se dá de forma desconexa. Pelo contrário, demonstra o domínio dos códigos textuais e emotivos que regem o jornalismo, concatenando informações com recursos linguísticos e sensíveis.

0 fecho do texto também entrelaça o ordinário e a vida cotidiana com o extraordinário, o doloroso e o melancólico, em uma chave afetiva que Le Breton (2004, p 624-625) entende como perpétua, uma vez que "a emoção não está necessariamente ligada a um evento forte ao sentido. As rotinas do cotidiano não são menos propícias à afetividade. 0 homem é religado ao mundo por um permanente tecido de emoções e sentimentos. Ele está a todo instante afetado". Assim, a ênfase na miséria e na precariedade de condições de Mestre Pastinha torna visível algo que é notório à realidade brasileira (escassez e pobreza, sobretudo entre a população negra) e inevitável à condição humana (a finitude).

Nesse tecido de emoções costurado pelo universo dos jornais, o corpo de Pastinha toma significado na matéria - se mostra um dado socializado e semantizado (LE BRETON, 2009). Ele representa o descaso público, bem como as intenções da mídia que outrora o 
expunha na televisão; ele significa a morte de um conhecimento que se desfaz no seu corpo. Os sentimentos são manifestações simbólicas, integrando uma economia afetiva na qual as emoções constituem práticas discursivas permeadas por negociações de poder (REZENDE, 2002). Nesse caso, o Jornal do Brasil entra na disputa por significações recorrendo a recursos jornalísticos associados às emoções e aos sentimentos coletivos.

Figura 2 - Matéria publicada na revista Placar
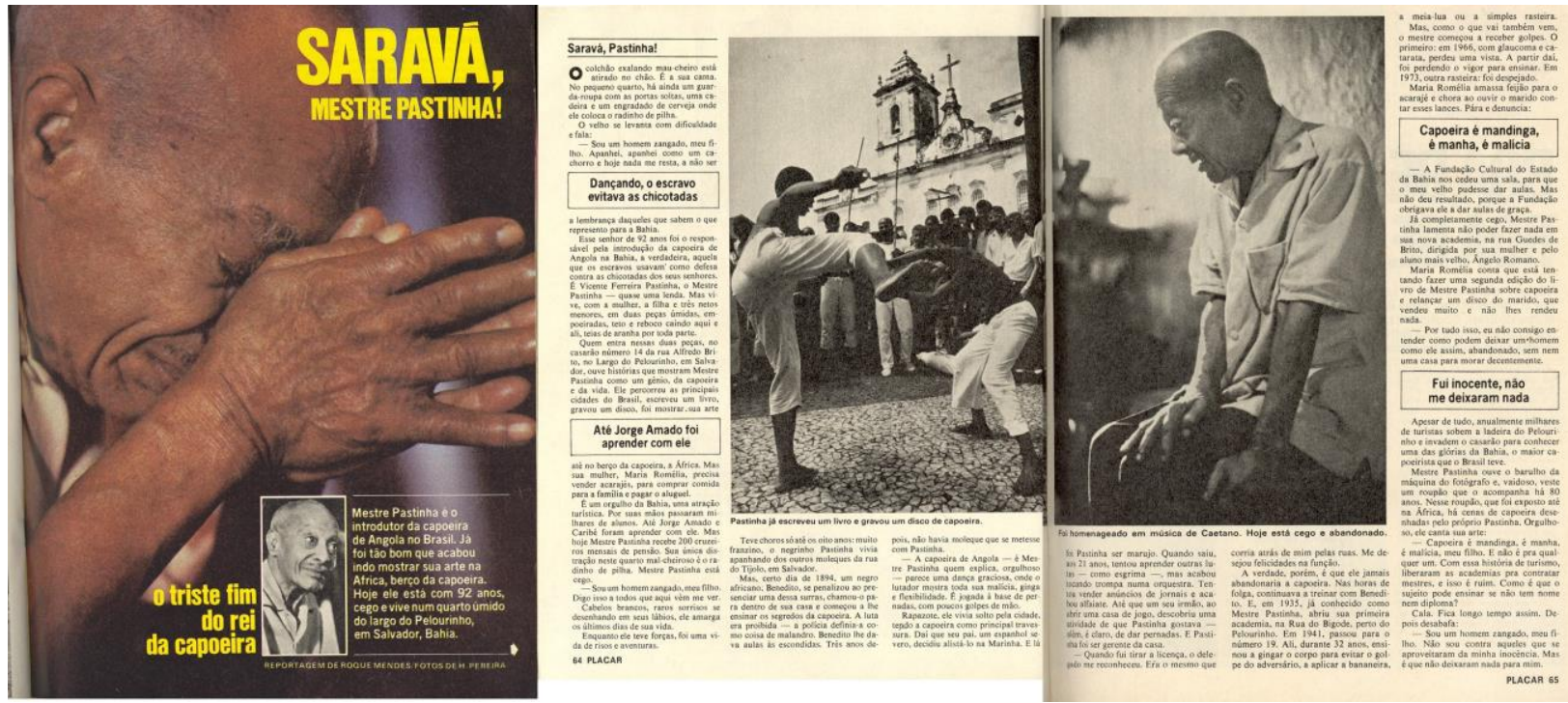

Fonte: Mendes (28 dez. 1979).

A perspectiva dos regimes de afetos observada no texto do Jornal do Brasil também pode ser identificada em uma matéria da revista Placar (figura 2) publicada dois meses antes, quando Pastinha já estava hospitalizado (provavelmente a entrevista feita na casa onde ele vivia com a mulher, o filho e os três netos foi realizada antes de sua internação e publicada posteriormente, em dezembro de 1979). Essa segunda matéria também recorre a recursos semelhantes de denúncia e apelo emotivo: título, imagens e olho conotam tristeza e exibem um corpo que expressa angústia e sofrimento, em contraposição a um corpo que outrora mostrava-se hígido, ativo e preparado.

0 texto revisita a trajetória de vida de Vicente Ferreira Pastinha, destaca as condições insalubres em que vivia com a família e usa a linguagem do corpo como metáfora da escrita, recurso curioso e potente a que se dará atenção especial e será analisado mais à frente. $\mathrm{Na}$ abertura, há uma foto de página inteira colorida fechada no rosto do capoeirista com as mãos fechadas, como se estivesse em oração. A imagem faz associação com o gesto 
feito aos pés do berimbau, antes do início de um jogo na roda de capoeira, a um gesto de devoção, de agradecimento, que também pode ser lido como súplica e sofrimento. Afinal, como escreveu Le Breton, "o rosto é, de todas as partes do corpo humano, aquela onde se condensam os valores mais elevados. Nele, cristalizam-se os sentimentos de identidade, estabelece-se o reconhecimento do outro, fixam-se qualidades da sedução" (2007, p. 70).

0 vasto campo de interpretação das imagens permite múltiplas leituras, por vezes, de sentidos opostos. No entanto, alguns desses sentidos se dão a ver de modo mais explícito. A leitura da foto da expressão facial de Pastinha humaniza, em primeira instância, o texto que a sucede nas próximas páginas da revista. Em reportagens, especialmente em revistas, há recursos e estratégias jornalísticas para trabalhar com as emoções, a começar pelo espaço disponível.

Ao abrir a página dupla, o leitor identifica e lê, primeiramente, as caixas em destaque, os "olhos da reportagem": "Dançando, os escravos evitavam as chicotadas"; "Até Jorge Amado foi aprender com ele"; "Capoeira é mandinga, é manha, é malícia"; "Fui inocente, não me deixaram nada". Além dos olhos, há o recurso à utilização de legendas informativas para as duas fotos: "Pastinha já lançou um disco e um livro"; "Foi homenageado em música de Caetano. Hoje está cego e abandonado". Emoção e informação aparecem mescladas nesses elementos da edição. 0 conteúdo informativo de olhos e legendas ressalta a capoeira como lazer e luta, como forma de resistência dos negros escravizados; e a credibilidade do conhecimento de Pastinha sobre a prática com alunos célebres como o escritor Jorge Amado. Destacam-se adjetivos que emitem juízos de valor associados à debilidade do corpo e à cegueira. Tais elementos informam previamente à leitura da matéria propriamente dita. Em outras palavras, preparam o leitor para o teor e o enquadramento que o texto adotará.

No senso comum ou no plano das representações sociais, o aprendizado social das emoções ensina que os indivíduos devem se insurgir contra injustiças. Justiça, no entanto, é um conceito móvel, que perpassa a moral e a ética. Assim, como aceitar que um mestre viva os últimos dias de sua vida em condições tão precárias? Os repórteres apelam para recursos que vão além do recorte e do relato dos fatos. Emitem juízos de valor, constroem o discurso de forma emotiva e sensível. Além de emitir a denúncia sobre o descaso do poder público com Mestre Pastinha - a matéria cita a Fundação Cultural da Bahia -, o texto também visa a agir diretamente nas emoções e no corpo dos leitores. 
No texto e nas fotos o corpo de Pastinha funciona como marcador temporal. Está implícita a ligação entre velhice e decadência corporal. Nessa perspectiva, Daniele Fortuna destaca que:

As emoções são também afetadas pela história de vida do indivíduo: os sofrimentos, as alegrias, as vitórias e as derrotas pelas quais passa. Nesse sentido, o tempo também desempenha papel fundamental. 0 passado influencia as expectativas de futuro e a forma como o sujeito lida com o presente. 0 futuro pode ser a antecipação de um gozo ou a projeção de um medo. (FORTUNA, 2015, p. 77).

Se for considerada a perspectiva do sujeito perfilado, a matéria sugere "uma vida inteira dedicada à capoeira e um fim amargurado, abandonado, em tal reconhecimento". 0 repórter Roque Mendes (1979), ao descrever etapas da vida de Pastinha, escreve: "Mas como o que vai também vem, o mestre começou a receber os golpes. 0 primeiro: em 1966, com glaucoma e catarata, perdeu uma vista. A partir daí, foi perdendo o vigor para ensinar. Em 1973, outra rasteira: foi despejado". 0 jogo de palavras utiliza verbos que fazem referência a movimentos ensinados pelo mestre na capoeira. 0 recurso estilístico aproxima o leitor corporalmente das experiências do personagem. Há uma identificação sensível com os fatos e as desgraças vividas por Pastinha, contribuindo para o afloramento de um estágio emocional latente.

\section{Considerações finais}

A leitura das duas matérias selecionadas aponta para uma reflexão sobre técnicas e estratégias jornalísticas do que podemos chamar de composição emocional, a partir da construção social das emoções e de sua expressão. Nos dois exemplos em discussão, destaca-se a fabricação da notícia tendo como matéria-prima o triste fim de vida de um mestre dedicado ao corpo e à capoeira. Pastinha fez de seu próprio corpo um instrumento de resistência, de pedagogia e sabedoria. Em seus últimos anos de vida, no entanto, o corpo outrora resistente foi exibido pelo jornalismo impresso como objeto de curiosidade de visitantes e turistas e de exposição por políticos que exploraram sua enfermidade e fragilidade.

As publicações sobre Mestre Pastinha, no final de sua vida, constituem material importante para se identificar um regime de afetos em fabricação por meio de material 
jornalístico. Um imaginário de papel acerca do personagem que destaca o lugar do corpo e das emoções.

Através da articulação jornalismo, corpo e emoção - fenômenos singulares, porém entrelaçados - é possível constatar a elaboração (e ratificação) desse regime jornalístico de afetos. Observa-se como as duas notícias estudadas sobre Pastinha comunicam um passado compartilhado, qual seja, o de uma sociedade brasileira que se fabricou ou se inventou, entre outros fatores, a partir do jornalismo impresso e de uma esfera pública letrada investida desde os seus primórdios pelas paixões e emoções intensas.

Se ódio, raiva e injúrias preenchiam o horizonte jornalístico do Brasil no século XIX, no século XX, Pastinha exemplificou como afetos também negativos continuavam a circular: dor, tragédia, drama e tristeza compunham um enredo social no qual a experiência de se emocionar retoma pressupostos conhecidos, próprios do universo do fait divers que caracteriza parte da esfera impressa e letrada brasileira. A pobreza e o infortúnio são velhos conhecidos da sociedade brasileira, sobretudo de sua população negra. Assim, esse regime jornalístico de afetos delineia as fronteiras simbólicas que autorizam percepções e sentimentos.

O desamparo e a melancolia de Pastinha abastecem o regime de afetos com piedade e compaixão, o que não é fortuito. É também importante destacar como as matérias sobre uma figura ligada à população afro-brasileira reeditam, no final do século $\mathrm{XX}$, afetos e percepções notadamente negativos. Na chamada grande mídia ou mídia comercial, a dor, de fato, parece ser uma constante nas tematizações jornalísticas sobre essa população e suas práticas, normatizando e demarcando os afetos em um terreno simbólico restrito: o da tristeza. Os relatos nas duas matérias do início dos anos 1980 não tocam apenas os afetos imediatos de quem narra, lê ou dissemina; mobilizam também um acervo sentimental que historicamente situou (e diferenciou) determinados corpos no âmbito das relações sociais. Afinal, como salienta Le Breton, "para que um sentimento (ou emoção) seja experimentado ou exprimido pelo indivíduo, ele deve pertencer, de uma forma ou de outra, ao repertório cultural do seu grupo" (2009, p. 126).

A escravidão foi elemento estruturante do repertório cultural e da própria formação do país. Da vida escravizada do século XIX à narrativa jornalística desamparada do final do século XX, cem anos transcorreram. Contudo, um saber afetivo conservou-se e (re)ensina as fronteiras em que as histórias e as práticas corporais ligadas à população negra se situam. É 
nesse sentido que as emoções, no processo de midiatização da vida de Pastinha, vão assumindo um estatuto midiático, isto é, assumem densidade simbólica que, sendo parte de um amplo processo social e histórico, se prestam a múltiplas reflexões. Destacam-se dessas reflexões a de caráter empírico, que toma o fim de vida de Pastinha em publicações impressas como objeto de estudo. Mas também se destaca a reflexão teórica que possibilita articular antropologia das emoções, jornalismo e corporeidade como chaves de leitura e interpretação da realidade; e, por fim, a reflexão interdisciplinar, característica central da Comunicação, que, a partir do olhar das mediações, viabiliza um debate em que pensar sobre um passado amplo e plural, do século XIX ao século XX, significa também pensar sobre o presente, sobretudo por conta da reinvenção que a capoeira experimenta na contemporaneidade, já no século XXI.

\section{Referências}

AMARAL, Márcia Franz. Jornalismo Popular. São Paulo: Contexto, 2006.

AMBROISE-RENDU, Anne-Claude. Le fait divers. In: KALIFA, Dominique; RÉGNIER, Philippe; THÉRENTY, Marie-Ėve; VAILLANT, Alain (orgs.). La civilisation du journal. Paris: Nouveau Monde, 2011. p. 979-997.

ANGRIMANI, Danilo. Espreme que sai sangue: um estudo do sensacionalismo na imprensa. São Paulo: Summus, 1995.

BARBOSA, Marialva. História da Comunicação no Brasil. Petrópolis: Vozes, 2013.

BARTHES, Roland. Structure du fait divers. In : BARTHES, Roland. Essais critiques. Paris: Seuil, 1964. p. 224-234.

DANTAS, Raquel Gonçalves. Narrativas de um corpo político à luz do feminismo angoleiro. In: SIQUEIRA, Denise da Costa Oliveira; FORTUNA, Daniele Ribeiro (orgs). Narrativas do eu: gênero, emoções e produção de sentidos. Porto Alegre: Sulina, 2019. p. 209-223.

FERREIRA, Vilma Moreira. A contribuição do Caderno B do Jornal do Brasil durante o período de repressão política do regime militar. In: ENCONTRO NACIONAL DE HISTÓRIA DA MÍDIA - Alcar. Anais [...]. Niterói: UFF, 2008. p. 1-12.

FORTUNA, Daniele Ribeiro. Emoções deslocadas: o nojo de Deus em Estamira. In: SIQUEIRA, Denise da Costa Oliveira (org.) A construção social das emoções: corpo e produção de sentidos na comunicação. Porto Alegre: Sulina, 2015. p. 75-89.

GÉLARD, Marie-Luce (org). Le sens en mots : entretiens avec Joël Candau, Alain Corbin, David Howes, François Laplatine, David Le Breton et Georges Vigarello. Paris: Petra, 2017. 
KALIFA, Dominique; RÉGNIER, Philippe; THÉRENTY, Marie-Ève; VAILLANT, Alain (orgs.). La civilisation du journal, Paris: Nouveau Monde, 2011.

LE BRETON, David. As paixões ordinárias: antropologia das emoções. Petrópolis: Vozes, 2009.

LE BRETON, David. A sociologia do corpo. Petrópolis: Vozes, 2007.

LE BRETON, David. Les émotions dans la vie quotidienne: approche critique de Klauss Scherer. In: Information sur les Sciences Sociales. Londres: SAGE Publications, 2004. p. 621-631.

MARTÍN-BARBERO, Jesús. Dos meios às mediações: comunicação, cultura e hegemonia. Rio de Janeiro: EdUFRJ, 2009.

MEDINA, Cremilda. Notícia, um produto à venda: jornalismo na sociedade urbana $\mathrm{e}$ industrial. São Paulo: Summus, 1988.

MOREL, Marco. As transformações dos espaços públicos: imprensa, atores políticos e sociabilidades na cidade imperial. Jundiaí: Paco Editorial, 2016.

MOTTA, Luiz Gonzaga. Análise crítica da narrativa. Brasília: Editora Universidade de Brasília, 2013.

PEDROSO, Rosa Nívea. A construção do discurso de sedução em um jornal sensacionalista. São Paulo: Annablume, 2001.

REZENDE, Claudia Barcellos. Mágoas de amizade: um ensaio em antropologia das emoções. Mana, Rio de Janeiro, v. 8, n.2, p. 69-89, 2002.

SILVA, Gislene. Para pensar critérios de noticiabilidade. Estudos em Jornalismo e Mídia, Florianópolis, v. 2, n. 1, p. 94-107, 2005.

SIQUEIRA, Denise da Costa Oliveira. Corpo, construção social das emoções e produção de sentidos na comunicação. In: SIQUEIRA, Denise da Costa Oliveira (org.) A construção social das emoções: corpo e produção de sentidos na comunicação. Porto Alegre: Sulina, 2015. p. 15-35.

SODRÉ, Nelson Werneck. História da imprensa no Brasil. Rio de Janeiro: Mauad, 1999.

TRAQUINA, Nelson. Teorias do jornalismo: porque as notícias são como são. Florianópolis: Insular, 2012.

VAILLANT, Alain. La Polémique. In: KALIFA, Dominique; RÉGNIER, Philippe; THÉRENTY, Marie-Ève; VAILLANT, Alain (orgs.). La civilisation du journal. Paris: Nouveau Monde, 2011. p. 969-978. 


\title{
Material jornalístico
}

BRITO, Reynivaldo. Mestre Pastinha - as mágoas de um ex-capoeirista. Revista Fatos e

Fotos Gente, Rio de Janeiro, 28 de abril de 1980.

PASTINHA, tradição da Bahia, em apuros. Jornal da Bahia, Salvador, 22 de outubro de 1971.

AOS 90 ANOS, cego e doente, Pastinha obtém alta do hospital. Jornal do Brasil, Rio de Janeiro, 26 de fevereiro de 1980. Caderno B.

PASTINHA ameaçado. Jornal do Brasil, Rio de Janeiro, 6 de junho de 1971.

TELEGRAMA afasta Pastinha. Jornal do Brasil, Rio de Janeiro, 26 de outubro de 1971.

MENDES, Roque. Saravá, Mestre Pastinha. Revista Placar, São Paulo, 28 de dezembro de 1979.

CASA de Mestre Pastinha vai ser local turístico. O Globo, Salvador, 16 de junho de 1971.

SIMÕES, Bené. 0 triste aniversário de Pastinha. Jornal 0 Movimento, São Paulo, 24 de abril de 1978.

\section{Tears of paper: Mestre Pastinha and the regimes of affects in print journalism}

\begin{abstract}
Emotions, feelings and affects are socially mediated phenomena, processed in the broad theater of human relations. Journalism composes such a phenomenon, contributing to the production, reproduction and reframing of sensibilities. This article aims to reflect on the expression of emotions in journalistic material, understanding that the affects identified relate to the act of feeling an emotion, but also to the symbolic and mediatized experience of the body and its practices. In methodological terms, our reflection is based on the reading of a set of old articles covering the last years of Mestre Pastinha's life, one of the most important names of Capoeira Angola in Brazil. For analysis purposes, two of these journalistic texts are studied in detail in this article. What meanings can be constructed based on an articulation of the body, emotions and media production? This is the basic question that instigates the reflection and analysis proposed in the article. The study is based on the anthropology of emotions, taking affects as culturally conditioned records that derive first from the repertoire of a social group rather than from natural or spontaneous forces.
\end{abstract}




\section{Keywords}

Narrative. Anthropology of emotions. Body. Capoeira Angola.

Production of meanings.

\section{Autora para correspondência}

Denise da Costa Oliveira Siqueira

denise.siqueira@yahoo.com.br

\section{Como citar}

SIQUEIRA, Denise da Costa Oliveira; MAJEROWICS, Fábio Grotz; DANTAS, Raquel Gonçalves. Lágrimas de papel: Mestre Pastinha e os regimes de afeto no jornalismo impresso. Intexto, Porto Alegre, n. 52, e103478, jan./dez. 2021. DOI: http://dx.doi.org/10.19132/1807-8583202152.103478

Recebido em 27/05/2020

Aceito em 22/02/2021

(c) $(1) \&$ 